Pesquisa Florestal Brasileira
Brazilian Journal of Forestry Research
http://pfb.cnpf.embrapa.br/pfB

\title{
Nota Científica \\ Registro da presença e danos causados por coleopteros em macaúba
}

\author{
Sebastián Giraldo Montoya ${ }^{1 *}$, Sergio Yoshimitsu Motoike ${ }^{1}$, Kacilda Naomi Kuki ${ }^{1}$, Cleber Macedo de Oliveira ${ }^{1}$, Isabela Gomes Honório² \\ ${ }^{1}$ Universidade Federal de Viçosa, Av. Peter Henry Rolfs, s/n, Campus Universitário Viçosa, CEP 36.570-900, MG, Brasil \\ ${ }^{2}$ Universidade Estadual Paulista, Rua José Barbosa de Barros, 1780, CEP 18.610-307, Botucatu, SP, Brasil
}

*Autor correspondente:
smagistergm@gmail.com

Termos para indexação:

Desfolhador

Palmeira

Praga

Óleo

Acrocomia aculeata

Index terms:

Defoliator

Palm

Pest

Oil

Acrocomia aculeato

Histórico do artigo:

Recebido em 08/08/2014

Aprovado em 02/12/2014

Publicado em 30/06/2015

doi: $10.4336 / 2015 . p f b .35 .82 .763$
Resumo - O objetivo deste trabalho foi identificar as espécies de besouros coletados em uma população nativa de macaúba (Acrocomia aculeata (Jacq.) Lodd), bem como caracterizar suas atividades, para futuros estudos da interação planta x inseto. Indivíduos adultos do gorgulho dos frutos e do besouro pardo foram capturados manualmente nos frutos e nos folíolos de plantas adultas de macaúba. Os insetos foram associados com o abortamento prematuro dos frutos e com a redução da área fotossintetizante das plantas.

\section{Recording and damage characterization of coleopters in macao palm}

\begin{abstract}
The objective of this work was to identify the species of beetles present in a macaw palm (Acrocomia aculeata (Jacq.) Lodd) native population as well as describe their activities, for further study of plant- insect interaction. Adult fruit weevils and brown beetles were collected manually in the fruits and the leaflets of adult plants of macaw palms. The insects were associated with the premature fruits abortion and with the reduction of the photosynthetic area of the plants.
\end{abstract}

Macaúba (Acrocomia aculeata (Jacq.) Lodd. ex Mart., Arecaceae) é uma espécie amplamente distribuída no Brasil desde os estados de São Paulo, Rio de Janeiro, Minas Gerais, até nas regióes Centro Oeste, Nordeste e Norte do Brasil (Aquino et al., 2008). Apesar de ser encontrada em regiões com solos arenosos e baixo índice hídrico, desenvolve-se melhor em locais onde há solos férteis (Lorenzi et al., 2010). Esta palmeira apresenta alto potencial como matéria prima para óleo-combustível. Embora seja considerada selvagem, a espécie encontrase em processo de domesticação. Por este motivo, estudos fitotécnicos, genéticos, entomológicos, entre outros, podem fornecer informações necessárias para a sua inserção no panorama agroflorestal.
A palmeira apresenta porte arbóreo quando adulta e é densamente recoberta por espinhos. Na fase reprodutiva, emite longas inflorescências bissexuais na forma de espádice. Aabertura das espatas florais inicia-se, geralmente, em setembro, e concentra-se no inicio do período chuvoso, entre os meses de novembro e janeiro. A macaúba apresenta protoginia, mecanismo reprodutivo no qual há separação temporal da maturação das flores pistiladas e estaminadas na mesma inflorescência (Ostrorog, 2009). O mesmo autor assegura que este mecanismo favorece a polinização cruzada (xenogamia), contribuindo para o sucesso reprodutivo da planta na presença de polinizadores eficientes. A protoginia é característica comum em flores polinizadas por besouros (Davis et al., 2008). 
Nuñez et al. (2005) reportam Curculionidae e Nitidulidae como as principais famílias de coleóptera como insetos polinizadores de Arecaceae. As inflorescências das Arecaceae também são visitadas por insetos oportunistas da ordem Hymenoptera, como Apis mellifera L. e Trigona spinipes (Fabricius, 1793) (Apidae).

O período de frutificação da palmeira é longo e seus frutos amadurecem principalmente entre setembro e janeiro. Os frutos são do tipo drupas globosas constituídos por epicarpo coriáceo, mesocarpo carnoso, endocarpo pétreo e endosperma sólido. $\mathrm{O}$ mesocarpo e endosperma são compostos basicamente por ácidos graxos, conferindo a característica oleaginosa do fruto (Lorenzi et al., 2010).

Vários fatores podem interferir na viabilidade dos frutos, e consequentemente na viabilidade ecológica e econômica de uma cultura. Os insetos interagem com as plantas e podem atuar de forma benéfica, oportunista e/ou danosa. Vários insetos, nos seus mais variados estádios de desenvolvimento, podem interferir no crescimento das plantas, sendo considerados pragas. Em palmeiras de importância econômica como o coco (Cocos nucifera L.), o dendê (Elaeis guineensis Jacq.) e o açaí (Euterpe oleraceae Mart.) é comum a herbivoria por coleópteros. $\mathrm{O}$ ataque destes insetos pode danificar as folhas, flores e frutos, resultando em uma redução da eficiência reprodutiva da planta. A identificação dos insetos potencialmente nocivos é, portanto, importante durante o manejo das culturas de interesse agronômico. Dentro deste contexto, este trabalho teve como objetivo realizar a identificação e a descrição das atividades das espécies de insetos capturados em uma população nativa de macaúba, para subsidiar informações para futuros estudos dentro do contexto agronômico.

O estudo foi conduzido no município de Acaiaca, MG, (481 m de altitude. Lat: $20^{\circ} 21^{\prime}$ 54" Sul Lon: $43^{\circ} 8$ ' 12" Oeste). Em média, cinco indivíduos adultos da palmeira e oito cachos (inflorescências) foram amostrados. O monitoramento foi realizado quinzenalmente entre os meses de dezembro de 2011 e janeiro de 2012, abrangendo o período de maior pluviosidade, com media de 13,04 mm (Instituto Nacional de Meteorologia, 2012). Este período abrangeu os estágios de floração, polinização e crescimento dos frutos da palmeira.

Os coleópteros adultos foram capturados de forma direta nas inflorescências e nas folhas da palmeira macaúba. Após a coleta, os espécimes foram acondicionados em câmara mortífera com acetato de etila e encaminhados para o laboratório de Entomologia Agrícola/ Departamento de Entomologia da Universidade Federal de Viçosa para triagem, montagem e envio para identificação.

Os insetos foram identificados como Parisoschoenus aff. obesulus Casey, 1922 (Coleoptera: Curculionidae: Baridinae: Baridini), conhecido como gorgulho dos frutos (Moura et al., 2009) (Figura 1a). Os indivíduos desta espécie têm atividade diurna, sendo mais ativos entre as 6 $\mathrm{h}$ e $8 \mathrm{~h}$ da manhã. Os insetos foram observados perfurando principalmente a base dos frutos recém-formados. Da mesma forma, observaram-se perfurações nas flores, poucas horas após a antese. Os curculionídeos utilizam o aparelho bucal para danificar o ovário da flor, o que ocasionava a queda prematura da mesma ou do fruto em crescimento (Figura 1b). Aproximadamente $24 \mathrm{~h}$ após o dano ocasionado por P. obesulus, os frutos se desprendiam espontaneamente das ráquilas, revelando, em alguns casos, evidências visíveis da herbivoria do inseto (Figura 1b). Em média, 25\% dos frutos e/ou flores afetadas abortaram precocemente. Uma semana após a antese, não foi possível observar a presença dos besouros nas inflorescências. Neste estudo, houve aborto total e/ou parcial dos frutos, em cachos com no máximo duas semanas após a antese. Para o total de cachos avaliados, $50 \%$ abortaram completamente e $5 \%$ parcialmente. A maioria dos frutos abortados apresentou sintomas claros do ataque de $P$. obesulus. Estima-se que a presença de adultos de $P$. obesulus, nas primeiras duas semanas após a antese, influenciou diretamente a queda prematura dos frutos de macaúba. Após este período, o abortamento dos frutos foi ainda observado, contudo sem sinais evidentes da ação do $P$. obesulus.

Segundo Bondar (1940), a larva de P. obesulus desenvolve-se sob as sépalas de frutos e flores do coqueiro, podendo ser encontrados, em alguns casos, nas bainhas foliares e pedúnculos florais, causando danos aos tecidos. Moura et al. (2009) constataram que $61 \%$ dos frutos de inflorescências com frutos normais e abortivos, em condições controladas e naturais abortaram, sendo que $9 \%$ dos frutos estavam infestados por P. obesulus. Ferreira et al. (1994) afirmaram que $P$. obesulus é uma das mais severas pragas do coqueiro, podendo ocasionar prejuízos superiores a $20 \%$ da produção. Entretanto, Moura et al. (2009) consideram errôneo afirmar que o abortamento dos frutos do coqueiro é causado por P. obesulus, visto que a oviposição do besouro ocorre apenas em frutos abortivos, sendo desnecessário a aplicação de inseticidas para o controle. 


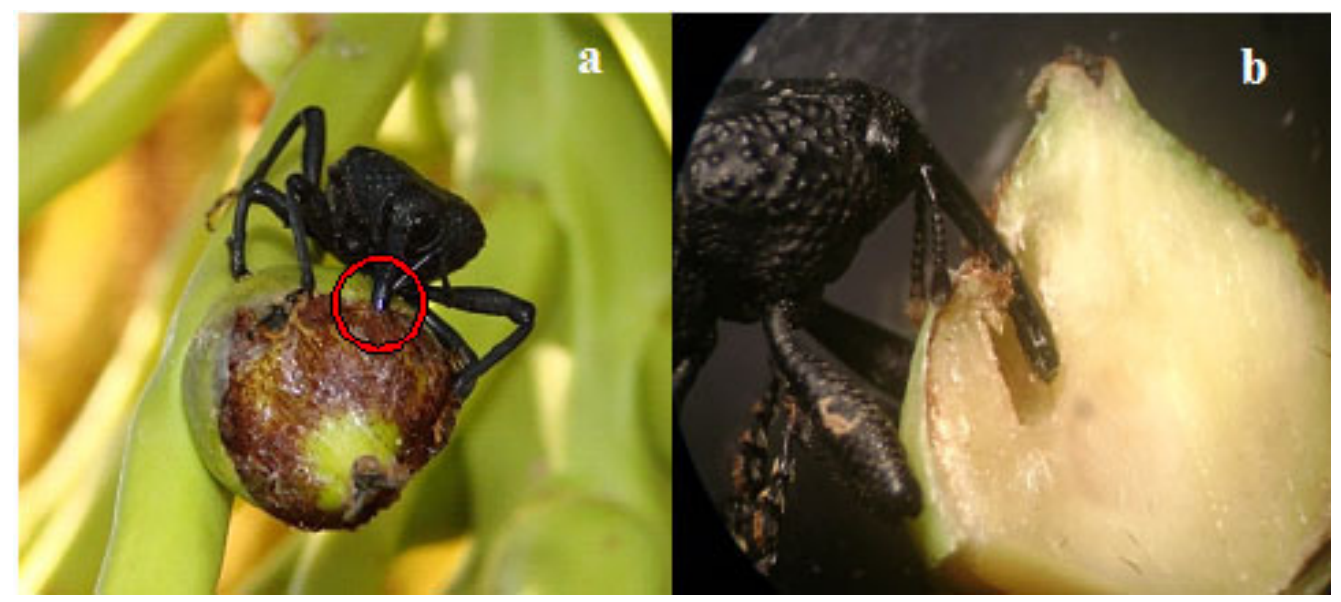

Figura 1. (a) Adulto de Parisoschoenus obesulus perfurando fruto de macaúba (Acrocomia aculeata) com 2 semanas após a antese. (b) Corte transversal da flor feminina, ilustrando a perfuração causada pelo P. obesulus (4X). Dezembro de 2011, Acaiaca, MG.

Os desfolhadores foram identificados como sendo Bolax flavolineata (flavolineatus) (Mannerheim, 1829) (Coleoptera: Scarabaeidae: Rutelinae: Geniatini) (Figura 2a), também conhecido popularmente como "besouropardo". Estes insetos foram capturados alimentando-se dos folíolos das palmeiras, principalmente dos folíolos em expansão. Os insetos apresentaram grande atividade de voo entre as plantas afetadas, principalmente entre $11 \mathrm{he}$ $13 \mathrm{~h}$. As plantas afetadas foram severamente desfolhadas, expondo as nervuras dos folíolos (Figura 2b).

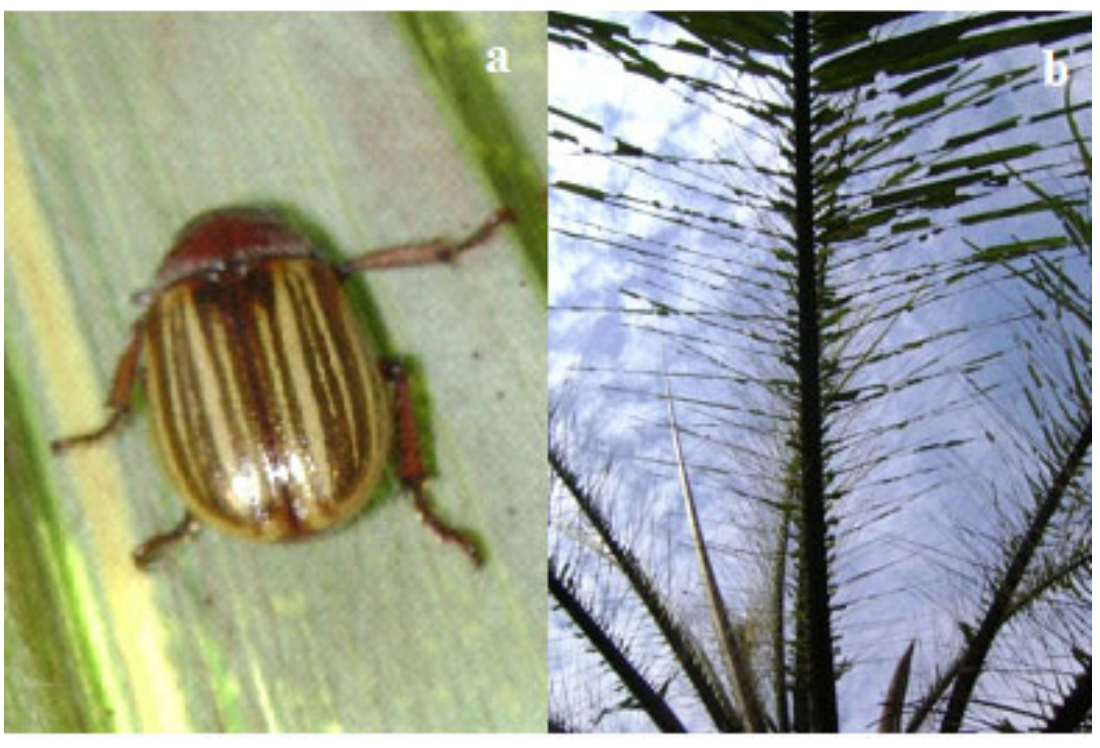

Figura 2. (a) Indivíduos de Bolax flavolineata na parte abaxial dos folíolos de Acrocomia aculeata. (b) Desfolha dos folíolos de Acrocomia aculeata causada por indivíduos de Bolax flavolineata. Dezembro de 2011, Acaiaca, MG.

Segundo Barbosa etal.(2014) os besouros desfolhadores constituem um grupo de insetos muito importante para a silvicultura brasileira. Estes estão incluídos em diversas famílias, principalmente Chrysomelidae, Curculionidae, Scarabaeidae e Buprestidae. Na família Scarabaeidae encontra-se a espécie Bolax flavolineatus. Zanuncio et al. (1993), afirmam que B. flavolineatus causa perfurações e rendilhamento das folhas, constituindo problema em plantios jovens de eucalipto. De acordo com Salvadori \& Silva (2004), no Rio Grande do Sul 
existem várias espécies de escarabeídeos associados a diferentes culturas. Contudo, na literatura não há estudos que apontem Bolax flavolineata como desfolhador de $A$. aculeata, tornando este trabalho pioneiro no levantamento de informações de possíveis pragas desta potencial cultura.

As observações realizadas mostraram que as flores, os frutos e as folhas da macaúba são alvos potenciais do ataque de insetos, causando tanto o abortamento precoce dos frutos como a redução da área foliar fotossintética, o que pode afetar o pleno desenvolvimento dos frutos. Este tipo de informação prevê problemas entomológicos que podem prejudicar a cultura da macaúba. Altas populações desses insetos podem determinar se a cultura é ou não viável em uma região específica. Igualmente, essas informações servirão de bases para outras investigações entomológicas e ecológicas na estimação da potencialidade desses indivíduos como pragas.

\section{Agradecimentos}

À professora Dra. Roberta de Melo Valente da Universidade Federal do Pará e ao professor Dr. Fernando Zagury Vaz de Mello da Universidade Federal de Mato Grosso pela identificação dos insetos.

\section{Referências}

AQUINO, F. G.; SILVA, M. R.; RATTER, J. A.; RIBEIRO, J. F.; VILELA, M. F.; OLIVEIRA, M. C. Distribuição geográfica das espécies Acrocomia aculeata (Jacq.) Lodd. ex Mart. e Caryocar brasilenese Cambess. no bioma Cerrado. In: SIMPÓSIO NACIONAL DO CERRADO, 9., 2008, Brasília, DF. Anais. Planaltina: EMBRAPA-CPAC, 2008. p. 1-6.

BARBOSA, L. R.; de QUEIROZ, D. L.; REIS FILHO, W. Cultivo do eucalipto: pragas de importância econômica. SANTOS, P. E. T. dos (Ed.). Sistemas de produção: cultivo do eucalipto. 4. ed. Brasília, DF: Embrapa, 2014. Disponível em: <https://www.spo.cnptia. embrapa.br/temaspublicados>. Acesso em: 01 set. 2014.
BONDAR, G. Insetos nocivos e moléstias do coqueiro (Cocos nucifera L.) no Brasil. Salvador: Tipografia Naval, 1940. 156 p.

DAVIS, C. C.; ENDRESS, P. K.; BAUM, D. A. The evolution of floral gigantism. Current Opinion in Plant Biology, v. 11, p. 4957, 2008 .

FERREIRA, J. M. S.; LIMA, M. F.; SANTANA, D. L.; MOURA, J. I. L. Pragas do coqueiro. In: FERREIRA, J. M. S.; WARWICK, D. R. N.; SIQUEIRA, L. A. (Org.). A cultura do coqueiro no Brasil. Aracaju: EMBRAPA-CPATC, 1994. p. 204-280.

INSTITUTO NACIONAL DE METEOROLOGIA, 2012. Disponível em: $<$ http://www.inmet.gov.br/portal/index.php?r=home/ page\&page=rede_estacoes_auto_graf $>$. Acesso em: 25 set. 2014.

LORENZI, H.; NOBLICK, L. R., KAHN, F.; FERREIRA, E. Flora Brasileira: Arecaceae (Palmeiras). Nova Odessa: Plantarum, 2010. $384 \mathrm{p}$.

MOURA, J. I. L.; FERREIRA, J, M, S.; SGRILLO, R. B.; VALLE, R. R.; ALMEIDA, A. A. F.; CIVIDANES, F. J.; DELABIE, J. H. C. Parisoschoenus obesulus Casey (Coleóptera: Curculionidae) não é praga de frutos novos do coqueiro. Neotropical Entomology, Londrina, v. 38, n. 2, mar./abr. 2009.

NUÑEZ, L. A.; BERNAL, R.; KNUDSEN, J. T. Diurnal palm pollination by mystropine beetles: is it weather-related? Plant Systematics and Evolution, v. 254, p. 149-171, 2005.

OSTROROG, D. R. V.; BARBOSA, A. A. A. Biologia reprodutiva de Geonoma brevispatha Barb. Rodr. (Arecaceae) em mata de galeria inundável em Uberlândia, MG, Brasil. Revista Brasileira de Botânica, v. 32, n. 3, p. 479-488, 2009.

SALVADORI, J. R.; SILVA, M. T. B. da. Coró do trigo, p. 211-232. In: SALVADORI, J. R.; ÁVILA, C. J.; SILVA, M. T. B. da (Ed.). Pragas de solo no Brasil. Passo Fundo: Embrapa Trigo; Dourados: Embrapa Agropecuária Oeste; Cruz Alta: Fundacep Fecotrigo, 2004. p. 211-232.

ZANUNCIO, J. C.; BRAGANÇA, M. A. L.; LARANJEIRO, A . L.; FAGUNDES, M. Coleópteros associados à eucalipto cultura nas regiões de São Mateus e Aracruz, Espírito Santo. Ceres, Viçosa, MG, v. 41, n. 232 , p. $584-590,1993$. 